Article

\title{
Aripiprazole and Haloperidol Activate GSK3 $\beta$-Dependent Signalling Pathway Differentially in Various Brain Regions of Rats
}

\author{
Bo Pan ${ }^{1,2}$, Xu-Feng Huang ${ }^{1,2}$ and Chao Deng ${ }^{1,2, *}$ \\ 1 Illawarra Health and Medical Research Institute, Wollongong 2522, Australia; bp355@uowmail.edu.au (B.P.); \\ xhuang@uow.edu.au (X.-F.H.) \\ 2 School of Medicine, University of Wollongong, Wollongong 2522, Australia \\ * Correspondence: chao@uow.edu.au; Tel.: +61-2-4221-4934; Fax: +61-2-4221-8130 \\ Academic Editor: Domenico De Berardis \\ Received: 9 February 2016; Accepted: 21 March 2016; Published: 28 March 2016
}

\begin{abstract}
Aripiprazole, a dopamine $D_{2}$ receptor $\left(D_{2} R\right)$ partial agonist, possesses a unique clinical profile. Glycogen synthase kinase $3 \beta$ (GSK3 $\beta$ )-dependent signalling pathways have been implicated in the pathophysiology of schizophrenia and antipsychotic drug actions. The present study examined whether aripiprazole differentially affects the GSK3 $\beta$-dependent signalling pathways in the prefrontal cortex (PFC), nucleus accumbens (NAc), and caudate putamen $(\mathrm{CPu})$, in comparison with haloperidol (a $\mathrm{D}_{2} \mathrm{R}$ antagonist) and bifeprunox (a $\mathrm{D}_{2} \mathrm{R}$ partial agonist). Rats were orally administrated aripiprazole $(0.75 \mathrm{mg} / \mathrm{kg})$, bifeprunox $(0.8 \mathrm{mg} / \mathrm{kg})$, haloperidol $(0.1 \mathrm{mg} / \mathrm{kg})$ or vehicle three times per day for one week. The levels of protein kinase B (Akt), p-Akt, GSK3 $\beta$, p-GSK3 $\beta$, dishevelled (Dvl)-3, and $\beta$-catenin were measured by Western Blots. Aripiprazole increased GSK3 $\beta$ phosphorylation in the PFC and NAc, respectively, while haloperidol elevated it in the NAc only. However, Akt activity was not changed by any of these drugs. Additionally, both aripiprazole and haloperidol, but not bifeprunox, increased the expression of Dvl-3 and $\beta$-catenin in the NAc. The present study suggests that activation of GSK3 $\beta$ phosphorylation in the PFC and NAc may be involved in the clinical profile of aripiprazole; additionally, aripiprazole can increase GSK3 $\beta$ phosphorylation via the Dvl-GSK3 $\beta$ - $\beta$-catenin signalling pathway in the NAc, probably due to its relatively low intrinsic activity at $\mathrm{D}_{2}$ Rs.
\end{abstract}

Keywords: antipsychotics; aripiprazole; $\beta$-catenin; bifeprunox; Dvl-3; GSK3 $\beta$; haloperidol

\section{Introduction}

Aripiprazole is an atypical antipsychotic drug with therapeutic effects on both positive and negative symptoms of schizophrenia, but reduced extrapyramidal side-effects (EPS) compared with typical antipsychotics (e.g., haloperidol) [1]. The exact mechanisms of aripiprazole remain unclear. Glycogen synthase kinase $3 \beta$ (GSK3 $\beta$ ) has been implicated in the pathophysiology of schizophrenia and the actions of antipsychotic drugs [2]. GSK3 $\beta$ is a major downstream regulator of dopamine $D_{2}$ receptors $\left(\mathrm{D}_{2} \mathrm{Rs}\right)$, which is targeted by most antipsychotics (including aripiprazole) [3]. Activation of $\mathrm{D}_{2}$ Rs facilitates the formation of the $\beta$-arrestin2-protein phosphatase $2 \mathrm{~A}$-protein kinase $\mathrm{B}$ (PKB or Akt) complex, resulting in dephosphorylation of Akt (inactivation), followed by dephosphorylation (activation) of GSK3 $\beta$ [4-6]. Aripiprazole has been shown to have effects on regulating the Akt-GSK3 $\beta$ signalling pathway [2]. For example, Seo et al. [7] have revealed that aripiprazole altered GSK3 $\beta$ activity in the frontal cortex. However, whether aripiprazole can affect GSK3 $\beta$ activity in other schizophrenia-related brain regions has not yet been studied. Our previous acute study [8] has found that acute administration of aripiprazole increased the phosphorylation levels of GSK3 $\beta$ in 
various brain regions, including the prefrontal cortex $(\mathrm{PFC})$, caudate putamen $(\mathrm{CPu})$, and nucleus accumbens (NAc). However, it is interesting that Akt did not show parallel changes with GSK3 $\beta$ after acute administration [8]. One possibility is that aripiprazole might affect GSK3 $\beta$ activity via alternative pathway(s) that is independent of Akt. One candidate pathway is the dishevelled (Dvl)-GSK3 $\beta$ - $\beta$-catenin signalling pathway. In vitro evidence has suggested that various antipsychotics (e.g., clozapine, haloperidol) increase the cellular levels of Dvl and $\beta$-catenin via affecting $D_{2}$ Rs $[9,10]$. In vivo studies have reported that antipsychotic drug administration (including aripiprazole and haloperidol) promoted phosphorylation of GSK3 $\beta$ and expression of Dvl and $\beta$-catenin in various brain regions [10-14]. It has been also revealed that administration of aripiprazole attenuated the decreased phosphorylation of GSK3 $\beta$ and reduced expression of $\beta$-catenin in the frontal cortex and hippocampus caused by immobilisation stress $[7,15]$. It should be noted that all these previous studies used intramuscular or subcutaneous injections to deliver aripiprazole. The effects of oral administration that mimic the clinical situation is of importance. Therefore, in this study we examined the Dvl-GSK3 $\beta$ - $\beta$-catenin signalling pathway after sub-chronic oral administration of aripiprazole.

Aripiprazole is a $D_{2} R$ partial agonist. Researchers have attributed the unique clinical profile of aripiprazole to its partial agonism at $D_{2}$ Rs $[16,17]$. However, the role that $D_{2} R$ partial agonism plays in the regulation of the Dvl-GSK3 $\beta-\beta$-catenin signalling pathway by aripiprazole is not clear. To investigate this issue, we chose a potent $\mathrm{D}_{2} \mathrm{R}$ partial agonist-bifeprunox [18] to compare with aripiprazole. Therefore, the present study examined the different effects of one-week oral administration of aripiprazole on the Akt-GSK3 $\beta$ and Dvl-GSK3 $\beta$ - $\beta$-catenin signalling pathways in three schizophrenia-related brain regions in comparison with a $\mathrm{D}_{2} \mathrm{R}$ antagonist-haloperidol and a $\mathrm{D}_{2} \mathrm{R}$ partial agonist-bifeprunox.

\section{Results}

\subsection{Effects of Antipsychotics in the Prefrontal Cortex}

Antipsychotic drug administration had significant effects on the expression of total GSK3 $\beta$ $\left(F_{3,20}=3.656, p<0.05\right), \mathrm{p}-\mathrm{GSK} 3 \beta\left(F_{3,20}=3.722, p<0.05\right)$ and the ratio of $\mathrm{p}-\mathrm{GSK} 3 \beta / \mathrm{GSK} 3 \beta\left(F_{3,20}=9.207\right.$, $p<0.01$ ) in the PFC, but had no effect on Akt, $p$-Akt, or the ratio of $p$-Akt/Akt (Figure 1A,D). Post hoc tests demonstrated that administration of aripiprazole significantly increased the protein levels of p-GSK3 $\beta$ by $47.7 \% \pm 6.4 \%(p<0.05)$, but reduced total GSK3 $\beta$ expression by $24.9 \% \pm 4.7 \%(p<0.05)$ compared with the control; the ratio of $\mathrm{p}-\mathrm{GSK} 3 \beta / \mathrm{GSK} 3 \beta$ was also increased by administration of aripiprazole $(p<0.01)$ (Figure 1B,D). Furthermore, the protein levels of Dvl-3 and $\beta$-catenin in the PFC were not significantly altered by any antipsychotic drug administration (Figure 1C,D).
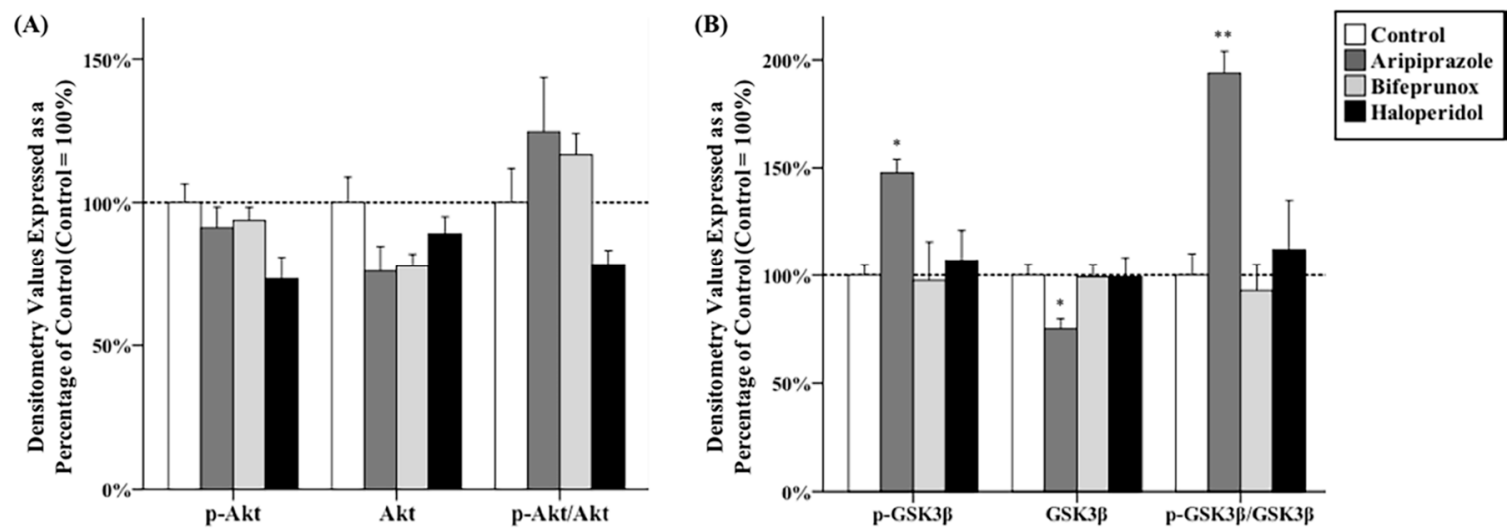

Figure 1. Cont. 


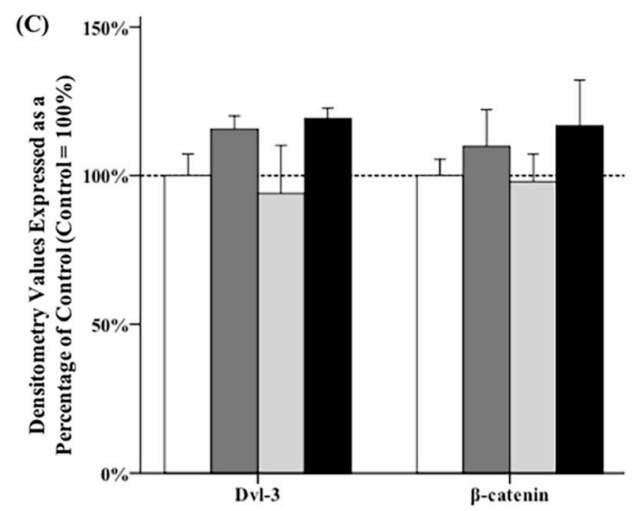

(D)

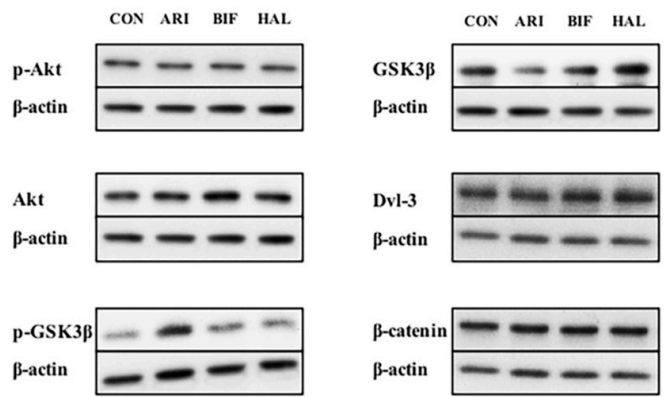

Figure 1. Effects of three antipsychotics in the prefrontal cortex. The effects of aripiprazole (ARI), bifeprunox (BIF), haloperidol (HAL), and control (CON) on the activity of protein kinase B (Akt) (A); glycogen synthase kinase $3 \beta$ (GSK3 $\beta)(\mathbf{B})$; and the expression of dishevelled (Dvl)-3 and $\beta$-catenin (C) were measured in the prefrontal cortex $\left({ }^{*} p \leqslant 0.05,{ }^{* *} p<0.01\right.$ vs. the control). All data were expressed as mean \pm S.E.M. The representative bands of Western blot are shown in (D).

\subsection{Effects of Antipsychotics in the Caudate Putamen}

One-way analysis of variance (ANOVA) tests indicated significant effects of antipsychotics on the protein levels of total Akt $\left(F_{3,20}=9.707, p<0.01\right)$ in the $\mathrm{CPu}$. Post hoc tests showed that the levels of total Akt were significantly increased by administration of bifeprunox $(+18.7 \% \pm 4.8 \%, p<0.05)$ and haloperidol $(+37.0 \% \pm 4.0 \%, p<0.01)$ in the $\mathrm{CPu}$ (Figure 2A,D); however, they did not affect the levels of $p$-Akt, nor the ratio of $p$-Akt/Akt. Additionally, the protein levels of Dvl-3 and $\beta$-catenin were not significantly affected by any antipsychotic drug administration in the $\mathrm{CPu}$ (Figure 2B-D).
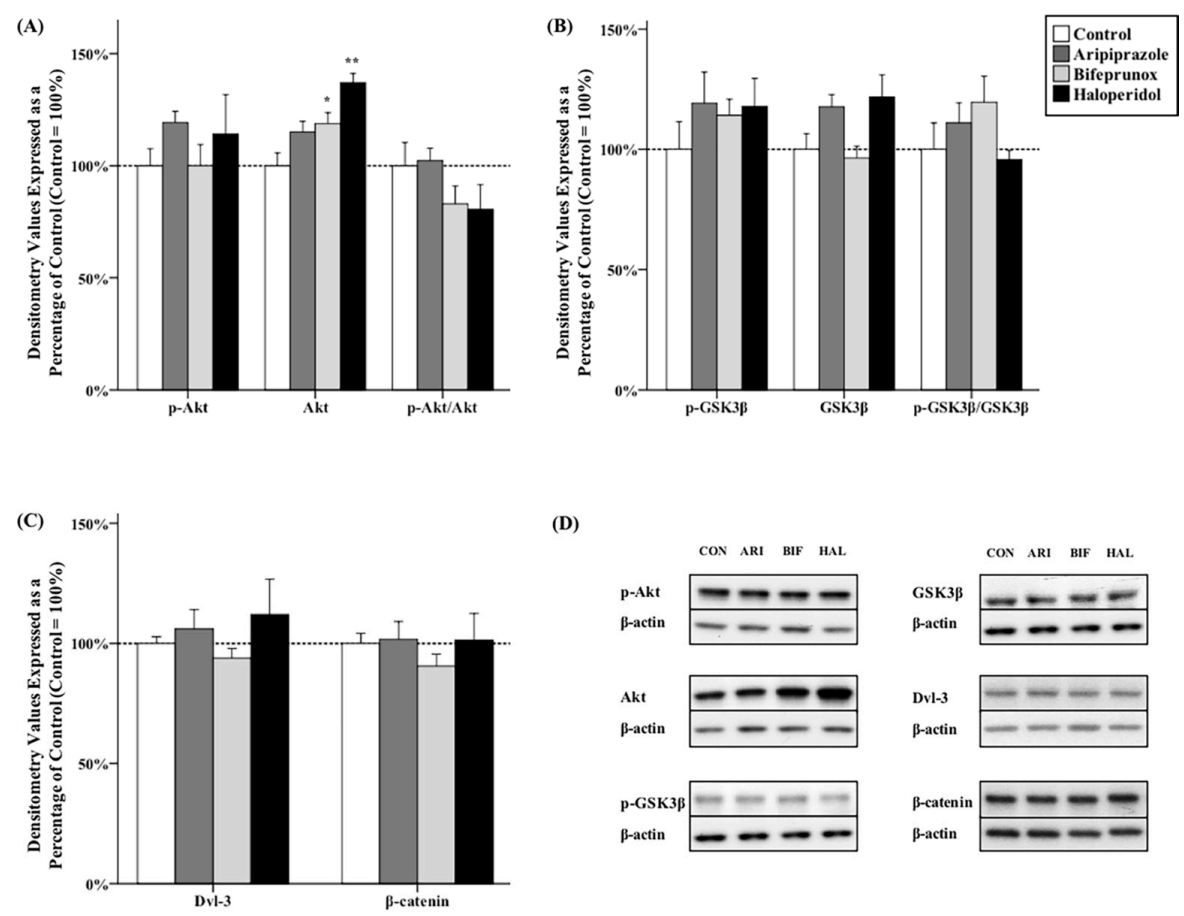

(D)

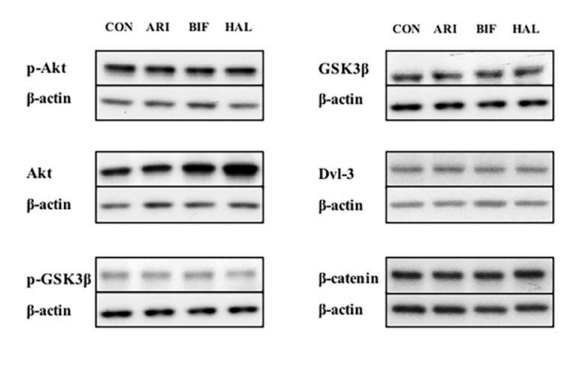

Figure 2. Effects of three antipsychotics in the caudate putamen. The effects of aripiprazole (ARI), bifeprunox (BIF), haloperidol (HAL), and control (CON) on the activity of Akt (A); GSK3 $\beta$ (B); and the expression of Dvl-3 and $\beta$-catenin $(\mathbf{C})$ were measured in the caudate putamen $\left({ }^{*} p \leqslant 0.05,{ }^{* *} p<0.01\right.$ vs. the control). All data were expressed as mean \pm S.E.M. The representative bands of Western blot are shown in (D). 


\subsection{Effects of Antipsychotics in the Nucleus Accumbens}

ANOVA tests revealed that antipsychotic drug administration had significant effects on the protein levels of $\operatorname{Akt}\left(F_{3,20}=6.792, p<0.01\right)$, GSK3 $\beta\left(F_{3,20}=25.381, p<0.01\right)$, p-GSK3 $\beta\left(F_{3,20}=11.817, p<0.01\right)$, the ratio of $p$-GSK3 $\beta /$ GSK3 $\beta\left(F_{3,20}=42.603, p<0.01\right)$, Dvl-3 $\left(F_{3,20}=4.121, p<0.01\right)$, and $\beta$-catenin $\left(F_{3,20}=10.718, p<0.01\right)$ in the NAc. Post hoc tests indicated that administration of all three chemicals was shown to be able to reduce the protein levels of total Akt (aripiprazole, $-25.9 \% \pm 5.9 \%, p<0.01$; bifeprunox, $-16.5 \% \pm 5.0 \%, p<0.05$; haloperidol, $-23.4 \% \pm 3.2 \%, p<0.01)$ in the NAc; however, no antipsychotic drug administration significantly affected the protein levels of $p$-Akt, nor the ratios of $p$-Akt/Akt (Figure 3A,D). Additionally, the expression of total GSK3 $\beta$ was reduced by both aripiprazole and haloperidol administration (aripiprazole, $-34.5 \% \pm 1.2 \%, p<0.01$; haloperidol, $-15.3 \% \pm 7.8 \%$, $p<0.05)$. Moreover, both aripiprazole and haloperidol administration was able to elevate the levels of p-GSK3 $\beta$ (aripiprazole, $+64.4 \% \pm 11.0 \%, p<0.05$; haloperidol, $+92.4 \% \pm 16.7 \%, p<0.01$ ) and the ratios of $p$-GSK3 $\beta /$ GSK3 $\beta$ (aripiprazole, $p<0.01$; haloperidol, $p<0.01$ ) (Figure 3B,D). Furthermore, it was shown that administration of aripiprazole was able to promote the expression of both Dvl-3 $(+64.1 \% \pm 11.5 \%, p<0.01)$ and $\beta$-catenin $(+46.5 \% \pm 10.7 \%, p<0.01)$; haloperidol administration also had a positive effect on the protein levels of both Dvl-3 $(+54.8 \% \pm 9.4 \%, p<0.05)$ and $\beta$-catenin $(+59.9 \% \pm 6.6 \%, p<0.01)$ (Figure 3C,D). Lastly, we found that the ratio of $p$-GSK3 $\beta /$ GSK3 $\beta$ is positively correlated with the expression of Dvl-3 in the NAc $(r=0.245, p<0.01)$ (Figure 4A); the ratio of $\mathrm{p}$-GSK3 $\beta /$ GSK3 $\beta$ is also positively correlated with the expression of $\beta$-catenin $(r=0.294, p<0.01)$ (Figure 4B).
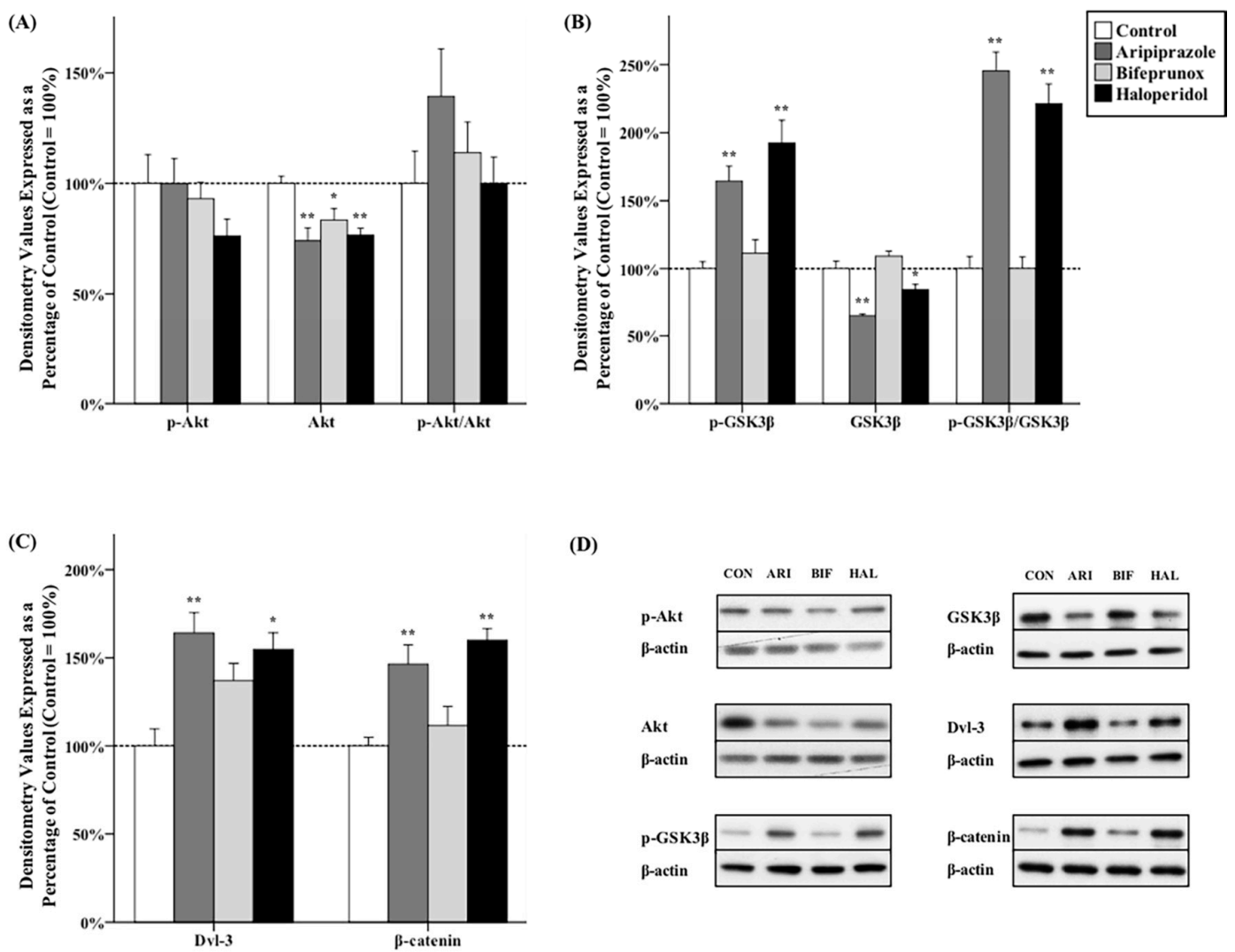

(D)

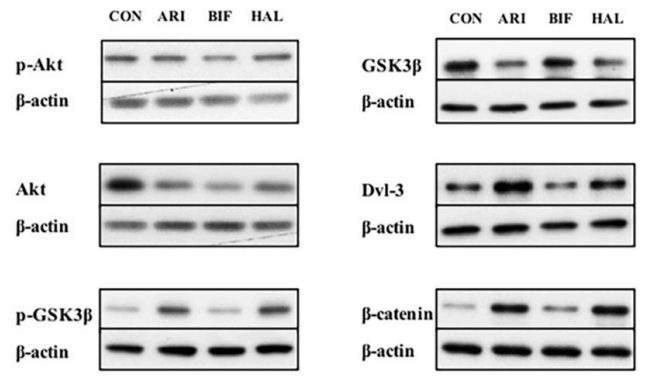

Figure 3. Effects of three antipsychotics in the nucleus accumbens. The effects of aripiprazole (ARI), bifeprunox (BIF), haloperidol (HAL), and control (CON) on the activity of Akt (A); GSK3 $\beta$ (B); and the expression of Dvl-3 and $\beta$-catenin $(\mathbf{C})$ were measured in the nucleus accumbens ${ }^{*} p \leqslant 0.05,{ }^{* *} p<0.01$ $v$ s. the control). All data were expressed as mean \pm S.E.M. The representative bands of Western blot are shown in (D). 

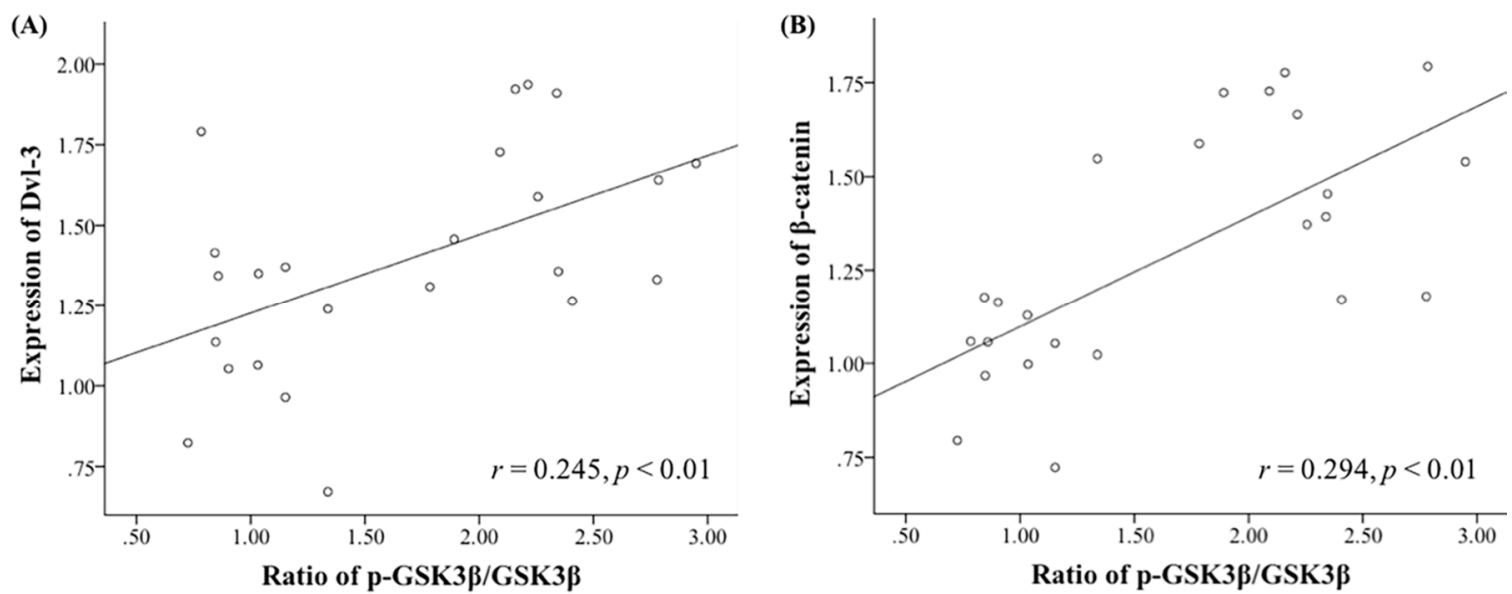

Figure 4. Correlations between the ratio of $\mathrm{p}-\mathrm{GSK} 3 \beta / \mathrm{GSK} 3 \beta$ and the expression of Dvl-3 and $\beta$-catenin in the NAc. The ratio of $\mathrm{p}-\mathrm{GSK} 3 \beta / \mathrm{GSK} 3 \beta$ is positively correlated with the expression of Dvl-3 (A); and with the expression of $\beta$-catenin in the NAc (B).

\section{Discussion}

The present study has examined the effects of aripiprazole on the Akt-GSK3 $\beta$ and Dvl-GSK3 $\beta$ - $\beta$-catenin signalling pathways in three key brain regions that are related to the pathophysiology of schizophrenia, in comparison with bifeprunox and haloperidol. Our findings have provided in vivo evidence that aripiprazole is able to alter the activity of GSK3 $\beta$ in the PFC and NAc. We also found that both aripiprazole and haloperidol, but not bifeprunox, activated the Dvl-GSK3 $\beta$ - $\beta$-catenin signalling pathway in the NAc.

A wide range of evidence has identified reduced phosphorylation levels and elevated GSK3 $\beta$ protein levels in the brains of schizophrenic patients, indicating hyper-activity of GSK $3 \beta$ in schizophrenia $[19,20]$. In addition, antipsychotics, including aripiprazole and haloperidol, have been shown to be able to induce inhibition of GSK3 $\beta$ function in various brain regions $[8,11-13,21]$. In the present study, both aripiprazole and haloperidol were able to increase the phosphorylation levels of GSK3 $\beta$ (the ratio of p-GSK3 $\beta /$ GSK $3 \beta$ ) in the NAc and PFC (only for aripiprazole), which is not completely consistent with the findings in previous studies $[7,8,11-13,15,21]$. It should be noted that the present study used oral administration to deliver the drugs (for one week) to mimic the clinical situations, which is different from the methods of other previous studies (e.g., intraperitoneal and subcutaneous injection); the dosages of antipsychotics used in this study are transferred from recommended clinical dosages, which are lower than those in previous studies $[7,11-13,15,21]$. Therefore, the results of the present study might be of more significance for clinic. However, whether these discrepancies are caused by different drug delivering methods requires further investigations.

However, the effects of aripiprazole and haloperidol on GSK3 $\beta$ were not completely consistent in every brain region in the present study. Therefore, by comparing the effects of aripiprazole with those of haloperidol, we may further understand the mechanisms of aripiprazole and elucidate its unique clinical profile. The present study has demonstrated that aripiprazole, but not haloperidol, increased the phosphorylation levels of GSK3 $\beta$ in the PFC. This effect is consistent with the result of our previous acute study [8] and another chronic in vivo study [7]. Since prefrontal dysfunction is linked to the negative symptoms of schizophrenia [22,23], it is suggested that suppression of GSK3 $\beta$ function in the PFC is very likely to contribute to the effects of aripiprazole on the negative symptoms of schizophrenia, which cannot be achieved by haloperidol $[7,8]$. Moreover, we have observed that aripiprazole increased GSK3 $\beta$ phosphorylation levels in the NAc in the present and previous acute study [8]; haloperidol also showed similar effects in the NAc presently and previously $[8,12,21]$. It is suggested that dysfunction of the NAc is related to the positive symptoms of schizophrenia [24]. Therefore, our finding further 
indicates that inhibition of GSK3 $\beta$ function in the NAc may contribute to the effects of antipsychotics on the positive symptoms of schizophrenia.

It is worth noting that Akt did not change in parallel with GSK3 $\beta$, which is not consistent with previous reports [12,21,25]. This might be explained by following reasons. First, Roh et al. [25] have reported that the phosphorylation of Akt induced by antipsychotics were much shorter in duration than those of GSK3 $\beta$. In the present study, the animals were sacrificed several hours after the last administration. Therefore, the phosphorylation levels of Akt might have already decreased to undetectable levels. This might be the major reason that we only observed the altered p-GSK3 $\beta$ levels, but not $p$-Akt. Second, there are two phosphorylating sites of Akt-Thr308 and Ser473, both could be affected by antipsychotic drug administration [4,21,25-27]. The present study has examined the Thr308 site of Akt only, since phospho-Thr308-Akt was involved in the $\mathrm{D}_{2}$ Rs-mediated Akt-GSK3 $\beta$ signalling [4,27]. However, Akt phosphorylated with either site induces phosphorylation of GSK3 $\beta$ at Ser9 that was examined in the current study. Thereby, it is possible that the elevated p-GSK3 $\beta$ levels in this study might be induced by phospho-Ser473-Akt from other signalling pathway(s), and further investigations are needed to study this issue. Lastly, GSK3 $\beta$ is a multi-targeted regulator. Antipsychotics might affect GSK3 $\beta$ via alternative pathway(s) rather than the $D_{2}$ Rs-mediated signalling pathway, such as the Dvl-GSK3 $\beta-\beta$-catenin signalling pathway.

We have examined the effects of antipsychotics on the Dvl-GSK3 $\beta-\beta$-catenin signalling pathway. It was observed that both aripiprazole and haloperidol administration increased the expression of Dvl-3 and $\beta$-catenin in accordance with the enhanced phosphorylation of GSK3 $\beta$ in the NAc, suggesting that antipsychotics is very likely to affect GSK3 $\beta$ activity via Dvl-GSK3 $\beta-\beta$-catenin pathway in this study. However, further studies (e.g., pharmacological or genetic intervention) are required to confirm this suggestion. In addition, it has been reported that antipsychotics (e.g., aripiprazole, haloperidol, clozapine, and risperidone) increased the expression of Dvl-3 and/or $\beta$-catenin in various brain regions, including the PFC and striatum [10,12,14]. It is worth noting that the studies by Alimohamad et al. [12] and Sutton et al. [14] have mixed NAc and CPu together, thus preventing identification of the sub-region(s) in which the levels of Dvl-3 and $\beta$-catenin were increased by antipsychotic drug administration. This study has separated NAc and $\mathrm{CPu}$, and demonstrated that antipsychotics affect Dvl-GSK3 $\beta-\beta$-catenin signalling specifically in the NAc. Taken together, it suggested that activation of Dvl-GSK3 $\beta-\beta$-catenin signalling in the NAc is a common route, through which different classes of antipsychotics exert their effects. Lastly, our results do not show any alteration in the expression of Dvl-3 and $\beta$-catenin in the PFC, which is inconsistent with the findings of previous studies $[10,12,14]$. The exact reason remains unclear. This may be because the previous studies $[10,12,14]$ used intramuscular or subcutaneous injection to deliver the drugs, whereas the current study used oral treatment with different dosages to mimic the clinical situation. Therefore, whether the effect of antipsychotics on Dvl-GSK3 $\beta$ - $\beta$-catenin signalling is treatment method-dependent requires further validation. Furthermore, one limitation of this study is that the samples have been investigated by only Western blots method, it is also worthy to further validate these findings using other methods such as qPCR and immunohistochemistry.

Previously, Min and colleagues [9] have investigated the interaction between the dopaminergic nervous system and Dvl-GSK3 $\beta$ - $\beta$-catenin signalling, and found that only $D_{2}$ Rs directly affected $\beta$-catenin distribution in the cell nucleus. The present study used aripiprazole, haloperidol and bifeprunox, all of which have strong affinity with $D_{2} R s[18,28]$. Haloperidol is a potent $D_{2} R$ antagonist, whereas aripiprazole and bifeprunox are $\mathrm{D}_{2} \mathrm{R}$ partial agonists. Previous studies have revealed that the intrinsic activity of aripiprazole at $\mathrm{D}_{2}$ Rs is weaker than that of bifeprunox (intrinsic activity at $\mathrm{D}_{2}$ Rs: aripiprazole vs. bifeprunox vs. dopamine $=86.0 \%$ vs. $95.1 \%$ vs. $100 \%$ ) $[22,29]$. Our results have demonstrated that administration of both aripiprazole and haloperidol, but not bifeprunox, had significant effects on altering the expression of Dvl-3 and $\beta$-catenin in the NAc. Therefore, first, blockade of $D_{2}$ Rs is (indirectly) linked to the activation of the Dvl-GSK3 $\beta$ - $\beta$-catenin signalling pathway. Second, it is very possible that aripiprazole competes with endogenous dopamine in the normal brain 
due to its relatively low intrinsic activity to reduce significantly the activity of endogenous dopamine, displaying an overall antagonising effect like haloperidol. In contrast, bifeprunox cannot achieve such effects, probably because of its relatively stronger intrinsic activity at $\mathrm{D}_{2} \mathrm{Rs}$. Taken together, our study suggests that a relatively low intrinsic activity at $D_{2} R s$ might be essential for a $D_{2} R$ partial agonist to achieve meaningful effects via affecting the Dvl-GSK3 $\beta$ - $\beta$-catenin signalling pathway.

\section{Materials and Methods}

\subsection{Animals and Drug Administration}

Male Sprague-Dawley rats (aged eight weeks) were obtained from the Animal Resource Centre (Perth, Australia). After arrival, all rats were housed in individual cages under environmentally controlled conditions (temperature $22^{\circ} \mathrm{C}$, light cycle from 07:00 a.m. to 07:00 p.m.), with ad libitum access to water and a standard laboratory chow diet. All experimental procedures were approved by the Animal Ethics Committee (Application \#AE11/02, 02/2011), University of Wollongong, and complied with the Australian Code of Practice for the Care and Use of Animals for Scientific Purposes (2004). All efforts were made to minimise animal distress and prevent suffering.

Before drug administration commenced, the rats were trained for self-administration of the cookie dough pellets without drugs. After 1-week training, rats were randomly assigned into one of the following four groups ( $n=6$ /group): aripiprazole $(0.75 \mathrm{mg} / \mathrm{kg}$, t.i.d. (ter in die), Otsuka, Tokyo, Japan); bifeprunox (0.8 mg/kg, t.i.d., Otava, Kiev, Ukraine); haloperidol (0.1 mg/kg, t.i.d., Sigma, Castle Hill, Australia); or vehicle for one week. Rats were offered cookies with drugs three times a day (at 06:00 a.m., 02:00 p.m. and 10:00 p.m.) and observed to ensure complete consumption of each pellet. The dosages were translated from recommended clinical dosages based on body surface area according to the FDA guidelines [30,31]. This drug administration method has been well established in our laboratory [32,33]. Specifically, a $0.75 \mathrm{mg} / \mathrm{kg}$ aripiprazole, $0.8 \mathrm{mg} / \mathrm{kg}$ bifeprunox and $0.1 \mathrm{mg} / \mathrm{kg}$ haloperidol dosage in rats is equivalent to $\sim 7.5, \sim 8$, and $\sim 1 \mathrm{mg}$ in humans (60 $\mathrm{kg}$ body weight), respectively, all of which are within the used/recommended clinical dosages [34-36]. It is worth noting that aripiprazole and bifeprunox induced over $90 \% \mathrm{D}_{2}$ receptor occupancy in rat brains at these dosages [18], and haloperidol reached approximately 70\% occupancy [37], all of which can display physiological and behavioural effects in rodents, without inducing EPS side-effects [18,38-40]. After one-week drug administration, all rats were sacrificed between 10:00 a.m. and 12:00 p.m. to minimise possible circadian-induced variation of protein expression. All animals were euthanised by using carbon dioxide. Brains were immediately dissected, frozen in liquid nitrogen and stored at $-80^{\circ} \mathrm{C}$ until further use.

\subsection{Micro-Dissection of Brain Samples}

Following a standard procedure used in our group [8], discrete brain regions were collected using brain microdissection puncture according to the brain atlas [41]. Briefly, three sections through the forebrain (Bregma 3.30 to $4.20 \mathrm{~mm}$ ) were collected for the PFC; and three sections through the striatum (Bregma 1.00 to $2.20 \mathrm{~mm}$ ) were collected for the $\mathrm{CPu}$ and NAc, respectively. Tissue dissected was kept at $-80{ }^{\circ} \mathrm{C}$.

\subsection{Western Blots}

The Western blot experiments were performed following standard procedures repeated in our previous studies [8,33]. Briefly, frozen tissue was homogenised with $9.8 \mathrm{~mL}$ NP-40 cell lysis buffer (Invitrogen, Camarillo, CA, USA) containing $100 \mu \mathrm{L}$ Protease Inhibitor Cocktail (Sigma-Aldrich, St. Louis, MO, USA), $100 \mu \mathrm{L} \beta$-Glycerophosphate (Invitrogen) and $33.3 \mu \mathrm{L}$ phenylmethylsulfonylfluoride (Sigma-Aldrich). The homogenised samples were centrifuged, and the supernatants were collected. Protein concentration of each homogenising solution was measured by using the DC Protein Assay (Bio-Rad, \#500-0111). After denaturing proteins, samples containing 
$10 \mu \mathrm{g}$ of protein were loaded into $4 \%-20 \%$ Criterion $^{\mathrm{TM}} \mathrm{TGX}^{\mathrm{TM}}$ Precast Gels (Bio-Rad, Hercules, CA, USA, \#5671095) in a Criterion ${ }^{\mathrm{TM}}$ Vertical Electrophoresis Cell (Bio-rad, \#1656001) at $200 \mathrm{~V}$ voltage for $50 \mathrm{~min}$, and then transferred electrophoretically to a polyvinylidene difluoride membrane in a Criterion ${ }^{\mathrm{TM}}$ Blotter (Bio-rad, \#1704071) at $100 \mathrm{~V}$ voltage for $60 \mathrm{~min}$. All membranes were blocked by $5 \%$ bovine serum albumin (BSA) for $60 \mathrm{~min}$ and incubated in primary antibodies (diluted in 1\% BSA) over night. Amersham Hyperfilm ECL (GE Healthcare, Chicago, IL, USA, \#28-9068-36) and Luminata Classico Western HRP substrate (Millipore, Billerica, MA, USA, \#WBLUC0500) were used to visualise the immunoreactive bands. The immunoreactive signals were quantified using Bio-Rad Quantity One software. The data of each targeted protein were then corrected based on their corresponding actin levels. Experiments were performed in duplicate to ensure consistency.

The antibodies used in the present study to examine the GSK3 $\beta$-involved pathways were anti-Akt (1:2000; Cell Signalling, Danvers, MA, USA, \#4691), anti-phosphor-Akt (Thr308) (1:1000; Cell Signalling, \#13038), anti-GSK3 $\beta$ (1:2000; Cell Signalling, \#5676), anti-phospho-GSK3 $\beta$ (Ser9) (1:1000; Cell Signalling, \#9322), anti-Dvl-3 (1:1000; Santa Cruz Biotechnology, Dallas, TX, USA, \#SC-8027) and anti- $\beta$-catenin (1:1000; Santa Cruz Biotechnology, \#SC-7963). Mouse anti-actin primary polyclonal antibody (1:10000; Millipore, \#MAB1501) was used to determine the actin levels. The secondary antibodies were HRP-conjugated anti-rabbit IgG antibody (1:3000; Cell Signalling, \#7074) and HRP-conjugated anti-mouse IgG antibody (1:3000; Cell Signalling, \#7076).

\subsection{Statistics}

All data was analysed using SPSS Statistics V22.0 program (IBM, New York, NY, USA). Data normality was tested using histograms and a Kolmogorov-Smirnov $Z$ test. For statistical evaluation, one-way analysis of variance (ANOVA) was performed if the data was normally distributed. The post hoc Dunnett $t$ test was then conducted to compare each drug treatment group with the control group. The results of Western blots were normalised by taking the average value of the control group as $100 \%$. The phosphorylation to total signal was calculated using the data from the same blot. Pearson's correlation test was used to analyse the relationships. A $p$-value of less than 0.05 was considered as statistically significant.

\section{Conclusions}

The present study explored the in vivo effects of one-week oral administration of aripiprazole on the GSK3 $\beta$-dependent signalling pathways in three brain regions that are associated with schizophrenia and the actions of antipsychotics, in comparison with haloperidol and bifeprunox. The current study provides in vivo evidence that inhibition of GSK3 $\beta$ activity in the PFC and NAc might be linked to the clinical profile of aripiprazole. This study further suggests that, like haloperidol, aripiprazole can activate Dvl-GSK3 $\beta-\beta$-catenin signalling in the NAc, which is probably due to the relatively low intrinsic activity at $\mathrm{D}_{2}$ Rs.

Acknowledgments: This study was supported by the Australian National Health and Medical Research Council project grant (APP1008473) to Chao Deng. The funding source had no role in study design; in data analysis and interpretation; in writing of the report; or in the decision to submit the manuscript for publication. We would like to thank Jiamei Lian and Michael De-Santis for their technical support for the animal treatment.

Author Contributions: Chao Deng and Bo Pan designed the study. Bo Pan performed the animal treatment. Bo Pan conducted experiments and analysed data. Bo Pan prepared the initial draft of the manuscript. Bo Pan, Chao Deng and $\mathrm{Xu}-\mathrm{Feng}$ Huang revised the manuscript and interpreted the data. All of the authors approved the final manuscript.

Conflicts of Interest: The authors declare no conflict of interest. 


\section{Abbreviations}

$\begin{array}{ll}\text { Akt } & \text { protein kinase } B \\ \mathrm{CPu} & \text { caudate putamen } \\ \mathrm{D}_{2} \mathrm{R} & \text { dopamine } \mathrm{D}_{2} \text { receptor } \\ \mathrm{Dvl} & \text { dishevelled } \\ \text { EPS } & \text { extrapyramidal side-effects } \\ \text { GSK3 } \beta & \text { glycogen synthase kinase } 3 \beta \\ \text { NAc } & \text { nucleus accumbens } \\ \text { PFC } & \text { prefrontal cortex }\end{array}$

\section{References}

1. Mailman, R.B.; Murthy, V. Third generation antipsychotic drugs: Partial agonism or receptor functional selectivity? Curr. Pharm. Des. 2010, 16, 488-501. [CrossRef] [PubMed]

2. Emamian, E.S. AKT/GSK3 signaling pathway and schizophrenia. Front. Mol. Neurosci. 2012, 5. [CrossRef] [PubMed]

3. Howes, O.; McCutcheon, R.; Stone, J. Glutamate and dopamine in schizophrenia: An update for the 21st century. J. Psychopharmacol. 2015, 29, 97-115. [CrossRef] [PubMed]

4. Beaulieu, J.M.; Sotnikova, T.D.; Yao, W.D.; Kockeritz, L.; Woodgett, J.R.; Gainetdinov, R.R.; Caron, M.G. Lithium antagonizes dopamine-dependent behaviors mediated by an AKT/glycogen synthase kinase 3 signaling cascade. Proc. Natl. Acad. Sci. USA 2004, 101, 5099-5104. [CrossRef] [PubMed]

5. Beaulieu, J.M.; Gainetdinov, R.R.; Caron, M.G. The Akt-GSK-3 signaling cascade in the actions of dopamine. Trends Pharmacol. Sci. 2007, 28, 166-172. [CrossRef] [PubMed]

6. Beaulieu, J.M.; Gainetdinov, R.R.; Caron, M.G. Akt/GSK3 signaling in the action of psychotropic drugs. Annu. Rev. Pharmacol. Toxicol. 2009, 49, 327-347. [CrossRef] [PubMed]

7. Seo, M.K.; Lee, C.H.; Cho, H.Y.; You, Y.S.; Lee, B.J.; Lee, J.G.; Park, S.W.; Kim, Y.H. Effects of antipsychotic drugs on the expression of synapse-associated proteins in the frontal cortex of rats subjected to immobilization stress. Psychiatry Res. 2015, 229, 968-974. [CrossRef] [PubMed]

8. Pan, B.; Chen, J.; Lian, J.; Huang, X.F.; Deng, C. Unique effects of acute aripiprazole treatment on the dopamine $\mathrm{D}_{2}$ receptor downstream cAMP-PKA and Akt-GSK3 $\beta$ signalling pathways in rats. PLoS ONE 2015, 10, e0132722. [CrossRef] [PubMed]

9. Min, C.; Cho, D.I.; Kwon, K.J.; Kim, K.S.; Shin, C.Y.; Kim, K.M. Novel regulatory mechanism of canonical Wnt signaling by dopamine $\mathrm{D}_{2}$ receptor through direct interaction with $\beta$-catenin. Mol. Pharmacol. 2011, 80, 68-78. [CrossRef] [PubMed]

10. Sutton, L.P.; Honardoust, D.; Mouyal, J.; Rajakumar, N.; Rushlow, W.J. Activation of the canonical Wnt pathway by the antipsychotics haloperidol and clozapine involves dishevelled-3. J. Neurochem. 2007, 102, 153-169. [CrossRef] [PubMed]

11. Alimohamad, H.; Sutton, L.; Mouyal, J.; Rajakumar, N.; Rushlow, W.J. The effects of antipsychotics on $\beta$-catenin, glycogen synthase kinase-3 and dishevelled in the ventral midbrain of rats. J. Neurochem. 2005, 95, 513-525. [CrossRef] [PubMed]

12. Alimohamad, H.; Rajakumar, N.; Seah, Y.H.; Rushlow, W. Antipsychotics alter the protein expression levels of $\beta$-catenin and GSK-3 in the rat medial prefrontal cortex and striatum. Biol. Psychiatry 2005, 57, 533-542. [CrossRef] [PubMed]

13. Li, X.; Rosborough, K.M.; Friedman, A.B.; Zhu, W.; Roth, K.A. Regulation of mouse brain glycogen synthase kinase-3 by atypical antipsychotics. Int. J. Neuropsychopharmacol. 2007, 10, 7-19. [CrossRef] [PubMed]

14. Sutton, L.P.; Rushlow, W.J. The effects of neuropsychiatric drugs on glycogen synthase kinase-3 signaling. Neuroscience 2011, 199, 116-124. [CrossRef] [PubMed]

15. Park, S.W.; Phuong, V.T.; Lee, C.H.; Lee, J.G.; Seo, M.K.; Cho, H.Y.; Fang, Z.H.; Lee, B.J.; Kim, Y.H. Effects of antipsychotic drugs on BDNF, GSK-3 $\beta$, and $\beta$-catenin expression in rats subjected to immobilization stress. Neurosci. Res. 2011, 71, 335-340. [CrossRef] [PubMed]

16. Hirose, T.; Kikuchi, T. Aripiprazole, a novel antipsychotic agent: Dopamine $\mathrm{D}_{2}$ receptor partial agonist. J. Med. Investig. 2005, 52, 284-290. [CrossRef] 
17. Burris, K.D. Aripiprazole, a novel antipsychotic, is a high-affinity partial agonist at human dopamine $\mathrm{D}_{2}$ receptors. J. Pharmacol. Exp. Ther. 2002, 302, 381-389. [CrossRef] [PubMed]

18. Wadenberg, M.-L.G. Bifeprunox: A novel antipsychotic agent with partial agonist properties at dopamine $\mathrm{D}_{2}$ and serotonin 5-HT1A receptors. Future Neurol. 2007, 2, 153-165. [CrossRef]

19. Beasley, C.; Cotter, D.; Khan, N.; Pollard, C.; Sheppard, P.; Varndell, I.; Lovestone, S.; Anderton, B.; Everall, I. Glycogen synthase kinase- $3 \beta$ immunoreactivity is reduced in the prefrontal cortex in schizophrenia. Neurosci. Lett. 2001, 302, 117-120. [CrossRef]

20. Koros, E.; Dorner-Ciossek, C. The role of glycogen synthase kinase- $3 \beta$ in schizophrenia. Drug News Perspect. 2007, 20, 437-445. [CrossRef] [PubMed]

21. Emamian, E.S.; Hall, D.; Birnbaum, M.J.; Karayiorgou, M.; Gogos, J.A. Convergent evidence for impaired AKT1-GSK3 $\beta$ signaling in schizophrenia. Nat. Genet. 2004, 36, 131-137. [CrossRef] [PubMed]

22. Tadori, Y.; Miwa, T.; Tottori, K.; Burris, K.D.; Stark, A.; Mori, T.; Kikuchi, T. Aripiprazole's low intrinsic activities at human dopamine $\mathrm{D}_{2} \mathrm{~L}$ and $\mathrm{D}_{2} \mathrm{~S}$ receptors render it a unique antipsychotic. Eur. J. Pharmacol. 2005, 515, 10-19. [CrossRef] [PubMed]

23. Benkert, O.; Muller-Siecheneder, F.; Wetzel, H. Dopamine agonists in schizophrenia: A review. Eur. Neuropsychopharmacol. 1995, 5, 43-53. [CrossRef]

24. Mikell, C.B.; McKhann, G.M.; Segal, S.; McGovern, R.A.; Wallenstein, M.B.; Moore, H. The hippocampus and nucleus accumbens as potential therapeutic targets for neurosurgical intervention in schizophrenia. Stereotact. Funct. Neurosurg. 2009, 87, 256-265. [CrossRef] [PubMed]

25. Roh, M.S.; Seo, M.S.; Kim, Y.; Kim, S.H.; Jeon, W.J.; Ahn, Y.M.; Kang, U.G.; Juhnn, Y.S.; Kim, Y.S. Haloperidol and clozapine differentially regulate signals upstream of glycogen synthase kinase 3 in the rat frontal cortex. Exp. Mol. Med. 2007, 39, 353-360. [CrossRef] [PubMed]

26. Smith, G.C.; McEwen, H.; Steinberg, J.D.; Shepherd, P.R. The activation of the Akt/PKB signalling pathway in the brains of clozapine-exposed rats is linked to hyperinsulinemia and not a direct drug effect. Psychopharmacology 2014, 231, 4553-4560. [CrossRef] [PubMed]

27. Beaulieu, J.M.; Sotnikova, T.D.; Marion, S.; Lefkowitz, R.J.; Gainetdinov, R.R.; Caron, M.G. An Akt/ $\beta$-arrestin 2/PP2A signaling complex mediates dopaminergic neurotransmission and behavior. Cell 2005, 122, 261-273. [CrossRef] [PubMed]

28. DeLeon, A.; Patel, N.C.; Crismon, M.L. Aripiprazole: A comprehensive review of its pharmacology, clinical efficacy, and tolerability. Clin. Ther. 2004, 26, 649-666. [CrossRef]

29. Tadori, Y.; Kitagawa, H.; Forbes, R.A.; McQuade, R.D.; Stark, A.; Kikuchi, T. Differences in agonist/antagonist properties at human dopamine $\mathrm{D}(2)$ receptors between aripiprazole, bifeprunox and SDZ 208-912. Eur. J. Pharmacol. 2007, 574, 103-111. [CrossRef] [PubMed]

30. U.S. Department of Health and Human Services; Food and Drug Administration; Center for Drug Evaluation and Research. Food and Drug Administration. Estimating the maximum safe starting dose in initial clinical trials for therapeutics in adult healthy volunteers. In Guidance for Industry; Food and Drug Administration: Rockville, MD, USA, 2005.

31. Reagan-Shaw, S.; Nihal, M.; Ahmad, N. Dose translation from animal to human studies revisited. FASEB J. 2008, 22, 659-661. [CrossRef] [PubMed]

32. De Santis, M.; Pan, B.; Lian, J.; Huang, X.F.; Deng, C. Different effects of bifeprunox, aripiprazole, and haloperidol on body weight gain, food and water intake, and locomotor activity in rats. Pharmacol. Biochem. Behav. 2014, 124, 167-173. [CrossRef] [PubMed]

33. Deng, C.; Pan, B.; Hu, C.H.; Han, M.; Huang, X.F. Differential effects of short- and long-term antipsychotic treatment on the expression of neuregulin-1 and ErbB4 receptors in the rat brain. Psychiatry Res. 2015, 225, 347-354. [CrossRef] [PubMed]

34. Mace, S.; Taylor, D. Aripiprazole: Dose-response relationship in schizophrenia and schizoaffective disorder. CNS Drugs 2009, 23, 773-780. [CrossRef] [PubMed]

35. Casey, D.E.; Sands, E.E.; Heisterberg, J.; Yang, H.M. Efficacy and safety of bifeprunox in patients with an acute exacerbation of schizophrenia: Results from a randomized, double-blind, placebo-controlled, multicenter, dose-finding study. Psychopharmacology 2008, 200, 317-331. [CrossRef] [PubMed]

36. Emsley, R. Drugs in development for the treatment of schizophrenia. Expert Opin. Investig. Drugs 2009, 18, 1103-1118. [CrossRef] [PubMed] 
37. Kapur, S.; VanderSpek, S.C.; Brownlee, B.A.; Nobrega, J.N. Antipsychotic dosing in preclinical models is often unrepresentative of the clinical condition: A suggested solution based on in vivo occupancy. J. Pharmacol. Exp. Ther. 2003, 305, 625-631. [CrossRef] [PubMed]

38. Han, M.; Huang, X.F.; Deng, C. Aripiprazole differentially affects mesolimbic and nigrostriatal dopaminergic transmission: Implications for long-term drug efficacy and low extrapyramidal side-effects. Int. J. Neuropsychopharmacol. 2009, 12, 941-952. [CrossRef] [PubMed]

39. Assie, M.B.; Dominguez, H.; Consul-Denjean, N.; Newman-Tancredi, A. In vivo occupancy of dopamine $\mathrm{D}_{2}$ receptors by antipsychotic drugs and novel compounds in the mouse striatum and olfactory tubercles. Naunyn Schmiedebergs Arch. Pharmacol. 2006, 373, 441-450. [CrossRef] [PubMed]

40. Natesan, S.; Reckless, G.E.; Nobrega, J.N.; Fletcher, P.J.; Kapur, S. Dissociation between in vivo occupancy and functional antagonism of dopamine $\mathrm{D}_{2}$ receptors: Comparing aripiprazole to other antipsychotics in animal models. Neuropsychopharmacology 2006, 31, 1854-1863. [CrossRef] [PubMed]

41. Paxinos, G.; Watson, C. The Rat Brain in Stereotaxic Coordinates; Elsevier Academic Press: San Diego, CA, USA, 2005.

(C) 2016 by the authors; licensee MDPI, Basel, Switzerland. This article is an open access article distributed under the terms and conditions of the Creative Commons by Attribution (CC-BY) license (http:/ / creativecommons.org/licenses/by/4.0/). 